\title{
Schizomyia botellus n.sp. - a new bud galling species from Apiaceae in Israel
}

\author{
NETTA DORCHIN ${ }^{1}$ \& AMNON FREIDBERG \\ Department of Zoology, Tel Aviv University, Tel Aviv 69978, Israel. \\ ${ }^{1}$ Email: ndorchin@post.tau.ac.il
}

In a recent paper (Dorchin \& Freidberg 2011) we reviewed the cecidomyiid fauna of the plant family Apiaceae in Israel. For one of the species that was described in that paper, we failed to provide details about the holotype depository, which we now provide in this note in order to make the species name available. We hereby describe the new species Schizomyia botellus Dorchin \& Freidberg, by reference to its full description in the above mentioned publication. Details of the holotype are as follows: ${ }^{\top}$, Israel, Mishor Paran, 17.iii.1995, N. Dorchin, reared from Deverra triradiata gall, deposited in the national collection of insects, Tel Aviv University, Tel Aviv, Israel (TAUI). Details about the paratypes, biology and distribution of the new species are found in Dorchin \& Freidberg 2011.

We are grateful to Irina Brake and Thomas Pape for their assistance in this matter.

\section{References}

Dorchin, N. \& Freidberg, A. (2011) The gall midges (Diptera: Cecidomyiidae) of Apiaceae in Israel. Zootaxa, 3044, $28-48$. 